\title{
Productivity in Insurance with Special Reference to Telecommunications*
}

\author{
by Norbert Graser
}

\section{Foreword}

Attempts to assess the effectiveness of business procedures have, in the past, concentrated less on "productivity" and rather more on "profitability" and "efficiency". This is without doubt partly because productivity can take many forms (on a national and business level, on a global or detailed procedural basis), under a variety of definitions that are themselves open to debate, but also because of the difficulty in obtaining the data and the actual material needed to produce practical results. The most eloquent definition serves little purpose if it has no practical application. The problem of productivity lies squarely in achieving practical results. Insurance, as a personnel-intensive service industry, has the additional difficulty of measuring administrative functions. Starting from the premise that measuring the productivity of labour is particularly important for the insurance industry, this paper examines various methods of doing just that: It provides a detailed critical appraisal of the various definitions of productivity and the statistical methods already known in the insurance business. With the kind permission of the author and his publishers we have pleasure in presenting the following extract concerning the influence of telecommunications on productivity in the insurance industry.

\section{Introduction}

Since computers were first introduced commercially to the insurance industry, technical progress has continued to improve data processing techniques. To keep abreast of competition, insurance companies have used such techniques intensively, the result over the last 10 years being the development of sophisticated data processing and information systems with comprehensive data bases. As there were no correspondingly sophisticated communication techniques this resulted in a high degree of centralisation in the insurance business. Large administrative offices employing large numbers of people arose, while on the other hand, small offices with small numbers of staff were disbanded. This development also implied a move away from the customer.

\footnotetext{
* From a series of publications from the Society for the Promotion of the Insurance Industry, Munich, founded by Professor Müller-Lutz, published by: Verein zur Förderung der Versicherungswissenschaft in München e.V.
} 
The first data communication facilities that came onto the market brought the opportunity to access the computer other than from its actual place of installation. Dedicated lines enabled company-internal infrastructures for communication with the computer to be implemented, allowing direct transfer of information from the internal computer processes to remote parts of the organisation.

The communication barriers that data processing systems tend to impose were overcome by communication routines, usually provided by the hardware manufacturer. As these routines were not always compatible the communication barriers were not fully overcome but were sometimes simply transferred to the end of the dedicated lines of individual companies. Additionally, communication with other partners was not always possible, or if so only under imperfect conditions. This usually meant the weaker partner conforming to the constraints imposed by the stronger. Full compatibility between terminals, computer capacity, data transmission equipment and transmission volumes is to date only feasible in closed systems.

In the meantime, digital technology is beginning to penetrate the field of cummunications. Digital transmission and communication techniques are incorporated in the existing telecommunication networks. This opens up the way for interconnecting separate communication systems and making different hardware systems compatible.

Current expectations as to future telecommunication infrastructures are based on the bad experiences of the past. The overcome the technical and organizational barriers to communication between sophisticated data processing systems we need an open communication system with clearly defined interfaces and communication standards that will allow any type of partner to intercommunicate. Participation in such a system must be economical and bring clear benefits.

The insurance industry therefore needs a cheap and reliable transport network that is accessible to almost every home and organisation and is fast enough to allow dialog between tha host computer and the end-user.

The scope and structure of the information involved will determine:

- The services required from the relevant post office.

- The terminals best suited for communication within the insurance company.

- The terminals required for communication between the company, the agencies and the customer.

Since the structure of the information and the way in which it is processed are largely dependent of the functions of the workplace, the communication requirements of an insurance company in-house and in the field are dealt with separately below.

\section{Deployment in the field.}

Many insurance companies are currently engaged in setting up so called sales force information systems or agency systems. The aim of these systems is as far as possible to release the sales representative or agent from administrative tasks, while at the same time giving him up-to-date information about his customer base in order to assist his sales effort and improve the service. 


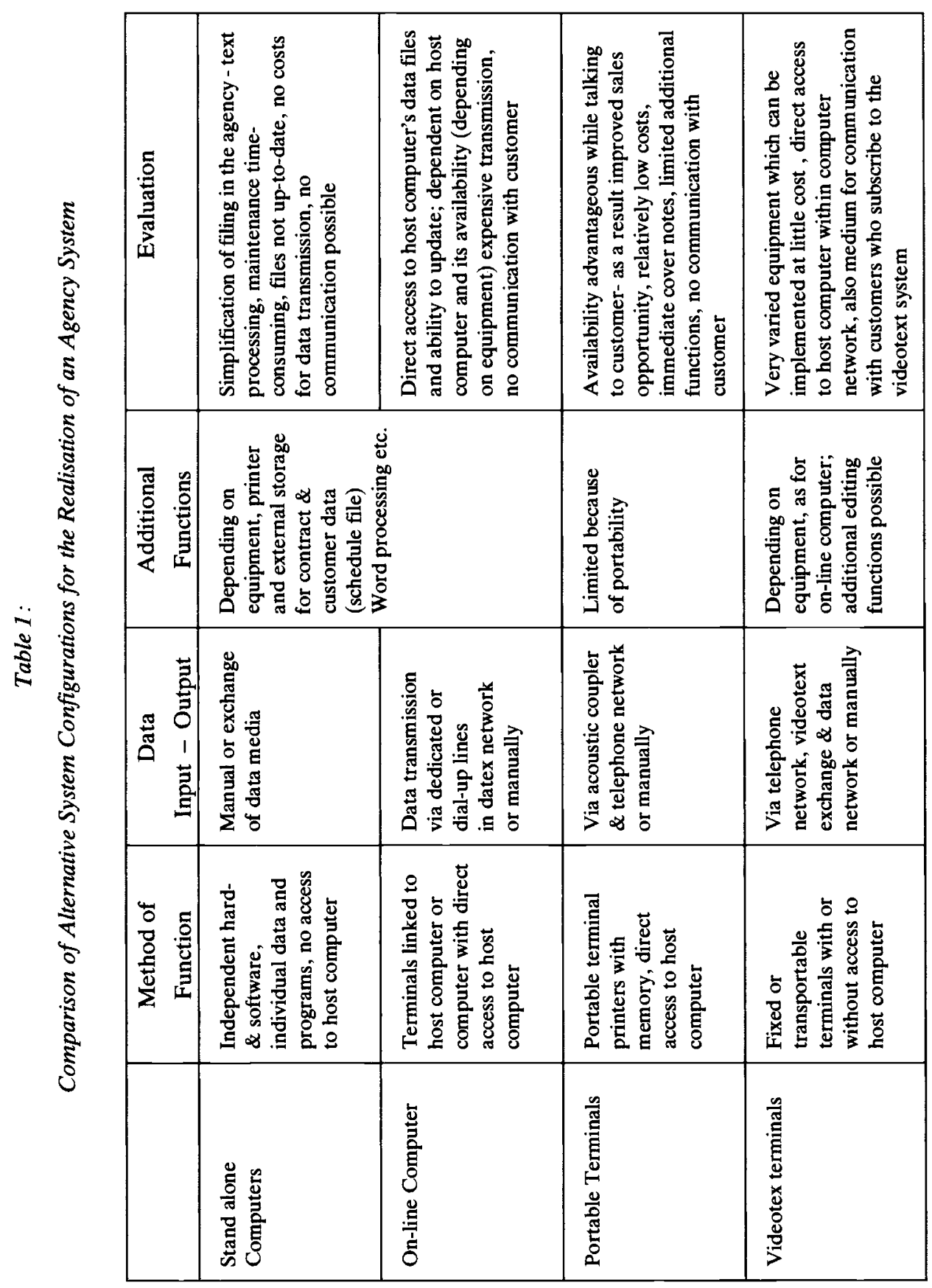


A well-designed sales force information system should contain more than just contractual data; for example, it could hold the customer's date of birth, number and age of children etc. The sales representative can then send a birthday message or act as consultant to the children when they come of age. The system also informs him of expiry of existing contracts and can in many cases often allow the customer base to be selected according to criteria such as insurance not held. Very often sales force information systems also include word processing functions, so that a standard letter can be sent automatically to a particular group of people. The sales representative is thus able to support his customer base and analyse it in terms of marketing criteria.

Table 1 shows a comparison of different system configurations suitable for implementing a sales force information system 1 .

A stand-alone computer, updated independently by an agency, has the significant disadvantage that the information is often not up-to-date. It is difficult, for example, for an agency to determine whether an invoice due from a customer has already been paid. So the use of a stand-alone computer would seem to be of advantage mainly for insurance brokers, where connection to a single host computer would actually be a disadvantage.

On-line computers, i.e relatively intelligent terminals communicating with a host computer via the Datex network, can always provide up-to-date information and also enable data to be input by the agency. The costs of implementing a sales force information system on this basis are, however, so high as to be feasible only for large sales operations. Moreover, dependency on the insurance company's host computer can have its disadvantages, for example when the system breaks down.

Another option offering great flexibility is the use of portable terminals the size of a portable typewriter. One insurance company can report on the use of portable terminals from its own experience. This company has now been intelligent terminals with a storage capacity of 80 kilobytes for nearly five years. These devices are equipped with a thermal printer and are connected to the company's host computer via the telephone network by means of a modem.

This terminal has the following functions ${ }^{2}$ : firstly, it is possible to connect directly to the host computer, for example if information about a contract is needed. To reduce transmission time, and thereby cost, so called form functions have been provided. To obtain an annuity calculation or a financial model the user first of all fills in a form which is stored in the terminal and then transferred to the host machine as one data packet.

Before the user begins working with the terminal he can obtain a printout of all its functions, thereby making operation very much easier. A further advantage of the portable terminal is that legally binding cover notes can be issued outside the insurance company's normal working hours. This could be needed, for example, for insuring motor vehicles. It is of course also useful in other branches of insurance to be able to issue a contract of insurance without having to wait for the application to run its full course.

\footnotetext{
${ }^{1}$ See also Association of Life Assurance Companies, Information Requirements and Methods of Information Communication for a Field Operation, 1982, p. 25-31.

${ }^{2}$ See Arheit G., Experience of Using Portable Terminals in Field Operation in the Insurance Industry; Versicherungswirtschaft, 1984, p. $237 \mathrm{ff}$.
} 
If you compare the conventional way of preparing an annuity calculation with its preparation using a portable terminal, you can see that not only is the time needed reduced from weeks to minutes, but that several of the tasks involved completely disappear. (Table 2).

Table 2:

Procedure for producing an annuity calculation by conventional methods and with the aid of a portable terminal.

\begin{tabular}{ll}
\hline Conventional Method & Portable Terminal \\
\hline $\begin{array}{l}\text { Obtain data from customer } \\
\text { Post information } \\
\text { (possibly via branch office) to head office } \\
\text { In-house mail distribution }\end{array}$ & $\begin{array}{l}\text { Obtain data from customer } \\
\text { Data transmission }\end{array}$ \\
$\begin{array}{l}\text { Data input } \\
\text { Calculation by computer }\end{array}$ & \\
Return results (possibly via branch office) & Calculation by computer \\
Presentation of results to customer on next visit & Return transmission of results \\
\end{tabular}

The benefits of combining data processing and telecommunications become particularly evident here. A number of stages and routine tasks are no longer needed while the amount of paper exchanged is drastically reduced. Productivity increases considerably.

The last option for implementing a sales force information system is the use of videotex terminals.

Here the user has a wide range of possibilities to choose from. As a minimum configuration, the TV must be connected to the telephone network by a modem, enabling the sales representative to access his customer base, which is stored on the host computer, via the computer network.

External storage media such as diskettes allow him to maintain his own data files or, with a printer, to do word processing. He may also be able to contact his customers directly via videotex, or write his own programs to offer additional services to his customers. The cost of hardware and data communications nevertheless remains within acceptable bounds.

The versatility and flexibility of this solution is such that viedotex will undoubtedly make a major contribution to the breakthrough of sales force information systems.

Once sales force information systems are widely introduced, a number of the insurance company's central tasks will disappear. Even local offices acting as central links between the sales operation and the head office will to a large extent be released from administrative tasks. This will enable the whole sales organization to devote its efforts to its real job of selling. 
One problem which the insurance company's head office will face must not be underestimated. The appropriate interfaces and software will need to be installed and must also conform to data protection requirements. The load on the computer will increase considerably, and finally, computer capacity must be available outside normal office hours.

\section{Installation at Head Ofiice}

The central services of an insurance company are involved in three types of functions, typical of other administrative centres. These are :

- typing and general office duties

- clerical work

- professional and managerial activities.

\subsection{Typing and general office duties}

This functional area includes all the work relating to text preparation and word processing plus internal post and messenger services, filing, maintenance of indexes and archives. The salient feature of this type of work is that it involves repetitive functions and no decision-making is required of the person doing the work.

The introduction of new telecommunications techniques will bring about major changes in the whole area of typing and general office duties.

Using typing as an example, Table 3 shows the evolution this area will undergo.

Table 3:

Typing procedure using different types of equipement

\begin{tabular}{lll}
\hline Equipment & Sender & \multicolumn{1}{c}{$\begin{array}{c}\text { Procedure } \\
\text { Recipient }\end{array}$} \\
\hline Typewriter & $\begin{array}{l}\text { Shortland dictation typing, } \\
\text { signing, filing of one or more } \\
\text { copies, collection in post } \\
\text { room, putting in envelopes, } \\
\text { franking, dispatch }\end{array}$ & \\
& $\begin{array}{l}\text { Audio-dictation, } \\
\text { otherwise as above }\end{array}$ & As above \\
Typewriter, Dictating & $\begin{array}{l}\text { Calling up \& completing } \\
\text { Machine }\end{array}$ & As above \\
Word Processing System & $\begin{array}{l}\text { specific text modules, } \\
\text { signing, collection in post } \\
\text { room, putting in envelopes, } \\
\text { franking and dispatch } \\
\text { Calling up \& completing }\end{array}$ & \\
& $\begin{array}{l}\text { specific text modules, } \\
\text { transmission }\end{array}$ & Call up on display unit \\
Teletex & &
\end{tabular}


In the first phase, where only a mechanical or electric typewriter is available, the clerk's work is dependent upon the typist. This dependency ceases to exist if a dictating machine is used. In the next stage, with the introduction of word processing systems, typing is simplified by text storage and improved correction methods.

Standard texts are often used, simply needing to be expanded or amended as required. Sometimes the printing of text modules can be initiated completely automatically by the computer.

The truly decisive step towards increasing productivity, however, only takes place in the next stage. The use of teletex in the workplace eliminates a number of procedures completely, such as all internal and external postal activity and the copying and archiving of documentation.

The improvement in productivity is not only restricted to the sender of the letter. For the recipient, too, a large number of previously necessary operations are eliminated as the information goes directly to the addressee who stores it electronically. This productivity improvement is particularly significant for the internal exchange of correspondence as it can be handled via local internal networks.

The present method of generating paperwork via the typing pool largely disappears.

It will not be possible in the foreseeable future to carry out all correspondence electronically as it cannot be assumed that all households will have the relatively expensive terminals that would be needed. The proportion of correspondence that can be transmitted electronically is estimated by experts at about $50 \%$ of the total. Each company should analyse its own correspondence in order to establish the structure of its communications.

\subsection{Clerical work}

The clerical worker, with few exceptions, mainly carries out well structured, repetitive tasks. His or her decision-making authority is small as the criteria for making decisions are already laid down. In an insurance company, clerical staff are primarily engaged either in checking and processing applications within a particular specialized area or in handling claims. Additional tasks that are not specifically administrative also occur in insurance companies, for example in the accounting function.

It has been possible in recent years to introduce much greater productivity into clerical activities. One of the main contributors has been interactive data processing. The time required to access stored data has decreased dramatically. Major aspects of clerical work, such as completion of insurance certificates and premium accounting, are now completely automated.

Despite the already extensive use of computers in clerical functions, telecommunications offer yet further opportunities for improving productivity in this area.

The multifunction workstation which could be available to clerical staff in the future could be equipped with a screen and keyboard allowing the following functions: text preparation (word processing), data processing and storage, terminal enquiry into data bases using host computers and communications through internal and external networks ${ }^{3}$.

\footnotetext{
${ }^{3}$ See Jurk R., Workstation and Communication in the Office of the Future; Electronic Text Communication, Pub. Kaiser W., Berlin, Heidelberg, New York, 1978, p. 463.
} 
This combination of different devices and functions allows the user to see his task through comprehensively from start to finish without recourse to intermediate general office services.

The new post office services allow data communication to be more economical than used to be the case. This is firstly because the terminals used for data transmission within the Datex network are much more expensive than, for example, a videotex terminal. Secondly, the actual transmission costs are much lower ${ }^{4}$.

This reduction in costs allows even small organizational units with correspondingly lower transmission requirements to take advantage of data communication. An insurance company, for example, can allow almost every sales representative to access the host computer within the context of a closed user group. In a broad-based business in particular, all the data relevant to an application can be entered directly by the sales representative. The computer first of all validates the entries, then confirms acceptance of the application. No data entry is needed by head office staff either on-line or via coding forms.

An insurance company using videotex in the computer network can even get the customer to do part of the work. The customer can obtain information from the computer such as conditions and amounts payable and an insurance policy could even be finalized at the terminal. However, since every insurance represents a declarable asset, this approach is questionable.

A suitably designed screen format could also replace the claims procedure in its present form. The clerk is thus released from paperwork and quickly obtains the accurate information he needs to process the claim.

The new data communication technologies will entail a rethinking of some fundamental principles. The fact that the clerk becomes an autonomus communication partner requires a certain adaptation of the legal structure of an insurance company. It places a question mark over the traditional rules governing responsibilities and powers of signatory ${ }^{5}$.

The question of centralisation of administrative functions again becomes relevant. The facility for data communication via a network that is cheaper to use than today's dedicated lines makes decentralisation attractive. Alternatively, a higher authority laying down guidelines on devolution of authority would in turn have a centralising effect.

\subsection{Professional and Managerial Activities}

Management and the staff reporting to it carry out activities that cannot normally be standardized and are not repetitive. These include obtaining and analyzing data, motivating staff and representing the company to the outside world - activities that require professionalism and flexibility.

Salary levels are higher, reflecting the increased reponsibility. Thus any effective support that could be given to such activities would be invaluable. In the past, computer systems were seldom able to provide help to managers and professional staff.

\footnotetext{
${ }^{4}$ See Graser, N., Methods of information Communication in the Insurance Companies, vol.4. 1983 , p. 48.

${ }^{5}$ See Witte E., Organizational Effects of New Communications Systems; Zeitschrift für Organization (Management Magazine) 1977, p. 363.
} 
Even here the new telecommunication techniques will prove to be beneficial. Information can be obtained more quickly and on a broader scale. Direct access to external data bases (e.g statistical bureaux or publishers) by means of videotex gives information considerably more quickly than by post or a personal visit.

Appropriate interfaces enable external data to be transferred to office automation systems, where it can be stored and processed, or combined with data from internal company data bases. The office automation system will also accommodate a variety of mathematical routines and allow the results to be printed in graphical form.

The user is guided by the system and can make corrections on the screen. The document, once prepared, can also be stored or transmitted. Thus the higher qualified employee can carry out the whole process himself without the need to call upon ancillary services.

Electronic communication thus reduces throughput times and speeds information flow. The consequence is not only an increase in productivity but also a reduction in the time taken up by the actual decision-making process. This in turn means that the impact of a decision is felt sooner, which is to the benefit of the company as a whole.

The new techniques of telecommunication betoken new organizational structures. The factors of time and space become less of a constraint.

Telephone and video conference facilities enable communication to take place between people who are physically separated, allowing project teams to be made up of people based in different locations. Data which may also be graphically displayed can be transmitted at the same time as the discussions. Computer conferencing offers even greater flexibility, enabling participants to contribute to discussions over non-specific periods of time and to send their contributions to one or more participants. This style of communication makes for efficiency and brevity.

Thus the need for people to attend meetings and to spend time travelling will be reduced. This will be even more the case once the various post offices are able to offer video conference services. In Germany this service is already available on a limited scale from special studios allowing not only the participants' speech but also documentation relevant to the discussion to be transmitted. 